\title{
Diagnostic work-up for the detection of malnutrition in hospitalized cancer patients
}

\author{
Camilla Leithold, MSc, ${ }^{a}$ Karin Jordan, MD, ${ }^{a}$ Franziska Jahn, MD, ${ }^{a}$ Timo Behlendorf, MD, ${ }^{\mathrm{b}}$ \\ Judith Schaffrath, MD, ${ }^{a}$ Carsten Müller-Tidow, MD, ${ }^{a}$ and Jörn Rüssel, $\mathrm{MD}^{\mathrm{a}}$
}

${ }^{1}$ Department of Hematology and Oncology, Martin Luther University Halle-Wittenberg, and ${ }^{2}$ Department of Hematology and Oncology, Hospital Martha-Maria, Halle (Saale), Germany

Background Malnutrition is a common complication in patients suffering from cancer. It is associated with a poor prognosis, reduced quality of life, increased chemotherapy-induced toxicity, and a decreased response to therapy.

Objective To evaluate and compare the use of various diagnostic tests for the detection of malnutrition in patients hospitalized for cancer treatment.

Methods In this single-center, non-interventional reliability study, the nutritional status of 50 patients with cancer was assessed using the Nutritional Risk Screening (NRS-2002), a bioimpedance analysis (BIA), and the measurement of laboratory parameters that reflect the serum visceral protein level. For statistical analysis, the comparison of means and the agreement of the methods were calculated.

Results NRS-2002, BIA, and lab parameters differed widely among patients classified as well-nourished or malnourished (10\%$80 \%$, depending on the method). Significant results in the comparison of means were observed for body mass index, serum protein, and some BIA parameters. The analysis of agreement identified a compelling agreement for pre-albumin and retinol-binding protein (RBP) (kappa $=0.81$ ).

Limitations Small sample size, heterogeneous group of patients, non-interventional reliability study.

Conclusion The tested diagnostic methods for detecting malnutrition did not have an evident agreement among each other with a limited exchangeability. In routine hospital practice several methods should be applied in order to identify cancer patients at risk of malnutrition.

Funding/sponsorship Fresenius Kabi provided the BIA-unit and software.

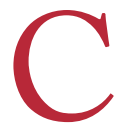
ancer patients are at high risk of developing malnutrition because of their consumptive disease and therapy-related side effects. ${ }^{1}$ The incidence of malnutrition in hospitalized cancer patients ranges between $38 \%$ and $71 \% .^{2,3}$ In tumor patients in particular, weight loss is associated with an unfavorable prognosis, reduced quality of life, increased chemotherapy-toxicity, and a diminished response to therapy. ${ }^{4}$ However, there is neither a uniform and accepted definition of malnutrition, nor an internationally recognized reference method for the assessment of malnutrition in terms of a gold standard. ${ }^{5-7}$ These facts complicate the diagnosis of malnutrition and a timely intervention to counteract the loss of body mass.

In this study, we compared the different methods for measuring nutritional status and identifying malnutrition in patients with hematologic and oncologic diseases. The nutritional status of eligible patients was assessed using the Nutritional Risk Screening 2002 (NRS-2002), a comprehensive bio- impedance analysis (BIA), and the measurement of laboratory parameters that reflect the serum visceral protein level (albumin, pre-albumin, and retinol-binding protein $[\mathrm{RBP}])$. We also evaluated the practicability and feasibility of these methods in the hospital setting.

\section{Methods}

This single-center, non-interventional reliability study was carried out at the University Hospital of the Martin-Luther-University Halle-Wittenberg, Germany. The study protocol was approved by the local ethics committee, and eligible patients had to sign an informed consent before enrollment. Patients were included if they were aged $\geq 18$ years and hospitalized for the beginning or the continuation of chemotherapy during the study period. Patients were ineligible for the following reasons: known drug or alcohol abuse, severe active infections, severe chronic or infectious diseases, abnormal laboratory values (aspartate aminotransferase, $>2.5$ times upper

Accepted for publication February 4, 2016. Correspondence: Camilla Leithold, MSc; camilla.leithold@uk-halle.de. Disclosures: The authors report no financial disclosures or conflicts of interest. JCSO 2016;14:155-161. (C2016 Frontline Medical Communications. doi: 10.12788/icso.0249. 
limit of normal [ULN; normal: women, 10-35 U/L; men, 10-50 U/L], alanine aminotransferase, $>2.5$ times ULN [normal: women, 10-35 U/L; men, 10-50 U/L], creatinine $>1.5$ times ULN [women, $0.5-1.0 \mathrm{mg} / \mathrm{dL}$; men, 0.6-1.2 $\mathrm{mg} / \mathrm{dL}]$ ), an implanted cardiac pacemaker or heart defibrillator, HIV/AIDS, arm or leg amputations, present parenteral nutrition, hemodialysis treatment, impaired thyroid metabolism, or inability to measure the exact height and weight. The nutritional status of the cancer patients was assessed after study entry by 3 different methods: the NRS2002, BIA, and laboratory parameters.

For the assessment of the nutritional status of inpatients, the European Society for Clinical Nutrition and Metabolism (ESPEN) recommends the use of the NRS-2002 as a validated screening method. ${ }^{8}$ This score also measures the individual risk of developing malnutrition because of disease and concomitant circumstances. It consists of a prescreening including questions for body-mass index (BMI), weight loss, reduced food intake, and severity of disease - and a mainscreening allowing a graduation of the nutritional disorder and the severity of the disease if one question of the prescreening is answered positively. Using a sum score the overall risk to develop malnutrition can be assessed ( 0 , no risk; 1-2, moderate risk; 3-7, high risk).

Laboratory parameters reflecting the serum visceral protein level - albumin, pre-albumin and RBP - were determined in the next blood sample as parameters for the nutritional status and, if applicable, the severity of an existing malnutrition. Reference values for each parameter are in Table $1 .{ }^{9}$

To estimate the body composition of each patient, BIA was conducted at least 1 hour after the last meal or liquid intake. BIA unit (BIACORPUS RX 4000), electrodes (BIAphaser Tabs) and software (BodyComp V8.5) were produced by MEDICALHealthCare $\mathrm{GmbH}$; Karlsruhe, Germany. The software for calculating the body compartments is commonly recommended for the use in epidemiological studies. ${ }^{10}$ The following values were obtained: resistance $(\mathrm{R})$, reactance $\left(\mathrm{Xc}_{\mathrm{c}}\right)$, phase angle, fat-free mass, fat mass, body cell mass (BCM), extracellular mass (ECM), ECM:BCM ratio.

\section{Statistics}

The data analysis was carried out using BIAS for Microsoft
Windows (version 9.16). Results were considered to be statistically significant at a $P$ value of $\leq .05$. Patient data were described using mean value, standard deviation, and range. For statistical analysis, patients were divided into groups according to the reference values for each method: patients whose values were in the reference range were classified as well nourished. Patients with values below the reference values were classified as malnourished. Furthermore, for the laboratory parameters and the NRS-2000 subdivisions reflecting the severity of malnutrition were established. The Kolmogorov-Smirnov test, modified by Dallal and Wilkinson, ${ }^{11}$ was used to test normal distribution of the data. For comparison of 2 independent, normally distributed samples the $t$ test was used, for not normally distributed data the Wilcoxon-Mann-Whitney-U-Test. To compare more than 2 independent samples the single factor variance analysis and for not normally distributed data the Kruskall-Wallis test were conducted. ${ }^{12}$ To determine the agreement between 2 methods and to assess the interrater-reliability regarding categorical parameters, Cohen's kappa was used. ${ }^{13}$

\section{Results}

\section{Patient characteristics}

A total of 50 patients ( 23 women and 27 men) with solid tumors and hematologic malignancies were included in the study during August 2012-January 2013 (Table 2).

\section{Nutritional status}

The nutritional status of cancer patients was assessed with the NRS-2002, laboratory values, BIA, and the BMI, using their respective reference values to categorize the patients as well nourished or malnourished (Table 3). The severity of malnutrition was evaluable by the NRS-2002 and albumin, pre-albumin, and RBP levels. The phase angle and the ECM:BCM ratio - both widely accepted predictors for the clinical progress of malnutrition - were used for the analysis of BIA.

The number of patients classified as well nourished and malnourished differed considerably between these diagnostic tests (10\%-80\%, depending on the method).

To assess the agreement between the different methods, the kappa-coefficient was calculated (Table 4). The

TABLE 1 Severity of malnutrition on the basis of laboratory values ${ }^{5}$

\section{Severity of malnutrition}

\begin{tabular}{|lcccc}
\hline & Normal & Mild & Moderate & Severe \\
\hline Albumin (g/L) & $35-45$ & $32-35$ & $28-32$ & $<28$ \\
\hline Pre-albumin (g/L) & $0.15-0.30$ & $0.12-0.15$ & $0.10-0.12$ & $<0.10$ \\
\hline Retinol-binding protein $(\mathrm{mg} / \mathrm{L})$ & $27-76$ & $<26$ & - & - \\
\hline
\end{tabular}


TABLE 2 Patient characteristics, tumor type, and results of different examinations for assessing the nutritional status of cancer patients

\section{Characteristic/result}

\begin{tabular}{|c|c|}
\hline Age, $y$ & $61[14](27-88)$ \\
\hline Height, $\mathrm{cm}$ & $\begin{array}{c}170.62[9.45] \\
(153.00-187.00)\end{array}$ \\
\hline Weight, kg & $\begin{array}{c}77.13[15.45] \\
(55.70-114.00)\end{array}$ \\
\hline $\mathrm{BMI}, \mathrm{kg} / \mathrm{m}^{2}$ & 26.49 [4.98] (18.8-42.2) \\
\hline $\begin{array}{l}\text { Screening, point value } \\
\text { NRS-2002 }\end{array}$ & $2.62[1.07](0-6)$ \\
\hline \multicolumn{2}{|l|}{ Laboratory values } \\
\hline Albumin (g/l) & 33.58 [4.49] (23.00-46.0) \\
\hline Pre-albumin (g/l) & $0.22[0.07](0.09-0.46)$ \\
\hline $\mathrm{RBP}(\mathrm{mg} / \mathrm{l})$ & $\begin{array}{l}42.74[14.55] \\
(16.50-77.10)\end{array}$ \\
\hline \multicolumn{2}{|l|}{ Bioimpedance analysis } \\
\hline Phase angle & $5.02[0.94](3.40-7.30)$ \\
\hline FFM, kg & $\begin{array}{l}57.42[11.35] \\
(41.90-83.60)\end{array}$ \\
\hline FFM, \% & $74.96[8.94](56.20-93.10)$ \\
\hline $\mathrm{FM}, \mathrm{kg}$ & $19.75[9.34](5.00-43.80)$ \\
\hline $\mathrm{FM}, \%$ & $25.00[8.84](6.90-42.30)$ \\
\hline $\mathrm{BCM}, \mathrm{kg}$ & $26.28[6.63](17.10-42.10)$ \\
\hline $\mathrm{BCM}, \%$ & $45.24[5.31](33.90-56.70)$ \\
\hline $\mathrm{ECM}, \mathrm{kg}$ & 31.81 [6.72] (22.0-49.70) \\
\hline $\mathrm{ECM}, \%$ & $54.20[5.68](36.60-64.80)$ \\
\hline $\mathrm{ECM}: \mathrm{BCM}$ & $1.22[0.25](0.76-1.84)$ \\
\hline Muscle mass cell content, $\%$ & $45.56[5.15](35.20-56.70)$ \\
\hline
\end{tabular}

\section{Tumor type}

Hematologic malignancies, n (\%)

$\begin{array}{lc}\text { Lymphoma } & 16 \\ \text { Leukemia } & 10 \\ \text { Multiple myeloma } & 9 \\ \text { MDS } & 3 \\ \text { Myelofibrosis } & 1 \\ \text { Solid Tumors, n (\%) } & 11(22) \\ \text { Gastrointestinal } & 4 \\ \text { Testicular } & 2 \\ \text { Leiomyosarcoma } & 2 \\ \text { Lung } & 1 \\ \text { Breast } & 1 \\ \text { Thymoma } & 1\end{array}$

$\mathrm{BCM}$, body cell mass; $\mathrm{BMI}$, body-mass index; $\mathrm{ECM}$, extracellular mass; FFM, fat-free mass; FM, fat mass; MDS, myelodysplastic syndromes; NRS, Nutritional Risk Screening; RBP, retinol-binding protein agreement between these methods was predominantly low (kappa $=-0.08-0.25)$, with the exception for pre-albumin and RBP (kappa $=0.81)$.

Based on the test results, patients were then classified as well nourished or malnourished on the basis of each parameter, and some further subdivisions were established. The subsequent comparison of means was made to show whether patients classified as malnourished by one method differed significantly with respect to the other examined parameters.

NRS-2002. The comparison of means showed no significant differences for patients classified under no, moderate, or high risk for develop malnutrition on the basis of their achieved point value. In the next step, patients with moderate and high risk were summed up to investigate whether they differed significantly from patients without risk. However, this comparison of means showed no significant differences between the 2 groups $(P \leq .05)$.

Body-mass index. A statistically significant correlation was observed for percentage of fat-free mass and percentage of fat mass: obese and overweight patients had significantly lower percentage of fat-free mass and a higher percentage of fat mass than did patients with normal weight (fat free mass: $66.76 \%$ overweight vs $79.64 \%$ normal weight; fat mass: $33.05 \%$ overweight vs $20.35 \%$ normal weight; $P \leq .05$ ).

Albumin. Patients with albumin $<28 \mathrm{~g} / \mathrm{L}$ had significantly lower values for pre-albumin $(0.12[\mathrm{SD}, 0.02] \mathrm{g} / \mathrm{L})$ and $\operatorname{RBP}(25.6[5.8] \mathrm{mg} / \mathrm{L})$, compared with patients within the reference range $(35-45 \mathrm{~g} / \mathrm{L}$; pre-albumin: 0.23 [0.06] $\mathrm{g} / \mathrm{L}$; RBP: 45.6 [13.1] $\mathrm{mg} / \mathrm{L})$ or in the range of mild malnutrition (32-35 g/ L; pre-albumin: 0.24 [0.06] g/ L; RBP: $46.5[13.0] \mathrm{mg} / \mathrm{L})$. Patients with albumin values in the range of $28-32 \mathrm{~g} / \mathrm{L}$ had a significantly higher ECM:BCM ratio $(1.4[0.3])$ than patients with albumin values in the range of $32-35 \mathrm{~g} / \mathrm{L}$ (1.1 [0.2]). An ECM:BCM ratio <1 seems to be a marker of a good nutritional status.

Pre-albumin. Patients with pre-albumin values within the reference range - consequently classified as well nourished by this method - had significantly higher levels of $\operatorname{RBP}(45.93$ [12.96] $\mathrm{mg} / \mathrm{L})$ and albumin $(34.53$ [4.0] g/L) than patients who were classified as malnourished (RBP: 23.10 [5.40] mg/L, albumin: 27.71 [2.28] g/L).

RBP. Patients with low RBP values had significantly lower albumin $(28.60$ [2.07] $\mathrm{g} / \mathrm{L})$ and pre-albumin values $(0.10[0.01] \mathrm{g} / \mathrm{L})$ than patients with higher $\mathrm{RBP}$ values (albumin: 34.13 [4.34] g/L; pre-albumin: 0.23 [0.06] g/L).

Phase angle. Patients whose phase angle corresponds to the age- and gender-specific reference did not differ from patients who were classified as malnourished by phase angle in terms of other nutritional characteristics $(P \leq .05)$.

ECM:BCM. Patients classified as well nourished because of their ECM:BCM ratio $(<1)$ had a significantly 
TABLE 3 Assessment of the nutritional status for each method: patients with values within reference range are classified as well nourished, all other were classified as malnourished. Reference values in parentheses.

\begin{tabular}{|c|c|c|c|c|c|}
\hline \multirow[b]{2}{*}{$\begin{array}{c}\text { Parameter } \\
\text { (reference value) }\end{array}$} & \multirow[b]{2}{*}{ Reference value } & \multicolumn{4}{|c|}{ Malnutrition risk } \\
\hline & & $\begin{array}{l}\text { Total } \\
\text { n (\%) }\end{array}$ & Mild (n) & Moderate (n) & Severe (n) \\
\hline $\begin{array}{l}\text { NRS-2002 } \\
\text { (0 points) }\end{array}$ & 29 & $21(42)$ & 0 & 7 & 14 \\
\hline $\begin{array}{c}\mathrm{BMI} \\
\left(\leq 18.5 \mathrm{~kg} / \mathrm{m}^{2}\right)\end{array}$ & 50 & $0(0)$ & 0 & 0 & 0 \\
\hline $\begin{array}{c}\text { Albumin } \\
\text { (35-52 g/L) }\end{array}$ & 22 & $28(56)$ & 12 & 11 & 5 \\
\hline $\begin{array}{c}\text { Pre-albumin (0.15- } \\
0.30 \mathrm{~g} / \mathrm{L})\end{array}$ & 43 & $7(14)$ & 5 & 3 & 1 \\
\hline $\begin{array}{c}\text { RBP } \\
(27-76 \mathrm{mg} / \mathrm{L})\end{array}$ & 45 & $5(10)$ & 5 & 0 & 0 \\
\hline $\begin{array}{l}\text { Phase angle } \\
\text { ( } \geq 5 \text {. percentile) }\end{array}$ & 33 & $17(34)$ & 0 & 0 & 0 \\
\hline $\mathrm{ECM}: \mathrm{BCM}(>1)$ & 10 & $40(80)$ & 0 & 0 & 0 \\
\hline
\end{tabular}

$\mathrm{BCM}$, body cell mass; $\mathrm{BMI}$, body-mass index; ECM, extracellular mass; NRS, Nutritional Risk Screening; RBP, retinol-binding protein

TABLE 4 Interobserver agreement and kappa statistics ${ }^{a}$

\begin{tabular}{ccccccc} 
& Albumin & Pre-albumin & RBP & NRS-2002 & Phase angle & ECM:BCM \\
\hline Albumin & - & 0.23 & 0.16 & 0.25 & 0.11 & 0.05 \\
\hline Pre-albumin & 0.23 & - & 0.81 & 0.19 & -0.04 & 0.08 \\
\hline RBP & 0.16 & 0.81 & - & 0.17 & -0.08 & 0.05 \\
\hline NRS-2002 & 0.25 & 0.19 & 0.17 & - & 0.24 & 0.09 \\
\hline Phase angle & 0.11 & -0.04 & -0.08 & 0.24 & - & 0.23 \\
\hline ECM:BCM & 0.05 & 0.08 & 0.05 & 0.09 & 0.23 & -
\end{tabular}

BCM, body cell mass; ECM, extracellular mass; NRS, Nutritional Risk Screening; RBP, retinol-binding protein

The greater the agreement of the methods the higher is the value of kappa $(K)$ : $K<0.20$ : weak, $K=0.21-0.40$ : low, $K=0.41-0.60$ : moderate, $K=0.61-0.80$ : strong, $\mathrm{K}=0.81-1.00$ : very strong agreement.

higher pre-albumin value $(0.24[0.09] \mathrm{g} / \mathrm{L})$, a higher phase angle $\left(6.52^{\circ}\left[0.58^{\circ}\right]\right)$ and a larger muscle mass cell content $(53.38[2.44] \%)$ than patients who were classified as malnourished using this method (pre-albumin: 0.21 [0.06] $\mathrm{g} / \mathrm{L}$; phase angle: $4.64^{\circ}\left[0.56^{\circ}\right]$; muscle mass cell content: $43.60[3.51] \%, P \leq .05)$.

\section{Discussion}

There is an unmet medical need for a standardized reference method for the detection of malnutrition in cancer patients that would be realistically applicable the in clinical routine. We compared the common diagnostic tests and studied the agreement among the different methods; a clinical preferable method could not be confirmed by this trial.
The NRS-2002 screening is suitable for assessing a patient's risk of suffering from malnutrition based on the detection of existing nutritional problems. Patients are identified when presenting with a BMI $<20.5 \mathrm{~kg} / \mathrm{m}^{2}$, unintentional weight loss in the previous 3 months, decreased food intake in the past week, or serious illness.

The determination of laboratory parameters and body composition using bioimpedance analysis is appropriate to quantify the extent of an existing malnutrition. Therefore, the aforementioned methods are used at different points in the diagnosis of malnutrition. Although the NRS2002 should be applied as part of the routine screening to identify patients at risk, the determination of laboratory parameters and body composition should be used for fur- 
ther diagnostic tests. Since the methods do not have a good agreement, no method can replace the other in their predication regarding the nutritional status of a patient.

As part of the NRS-2002, the BMI was calculated for each patient. There are different cut-off values for the diagnosis of malnutrition: The World Health Organization defines malnutrition at $\mathrm{BMI} \leq 18.5 \mathrm{~kg} / \mathrm{m}^{2}$, whereas ESPEN defines borderline underweight as BMI $\leq 20 \mathrm{~kg} / \mathrm{m}^{2}{ }^{8}$ In the present study, the mean BMI of the patients was 26.49 [4.98] $\mathrm{kg} / \mathrm{m}^{2}$. No patient was classified as malnourished; 1 patient with a BMI of $18.8 \mathrm{~kg} / \mathrm{m}^{2}$ was classified as borderline underweight. Compared with the other methods used, the BMI alone is not sufficient to reflect the nutritional status of a patient, because weight loss, decreased serum protein, and altered body composition could not be recognized. For example, in patients suffering from body water disorders, weight loss can be masked. ${ }^{5}$ For this reason, the interpretation of the BMI as a single parameter has to be done carefully with regard to other parameters and patients' history. The sole use of the BMI for the diagnosis of malnutrition cannot be recommended and it should no longer be a marker of malnutrition in clinical practice.

In the present study, the laboratory parameters albumin, pre-albumin, and RBP were determined to reflect the nutritional status of the patients. The interpretation of these values should be made in regard to further diagnoses, for example, liver and kidney dysfunction and increased inflammatory parameters. ${ }^{14,15}$ For this reason, patients with liver and kidney dysfunction and increased inflammatory parameters were excluded from participation in this study.

Albumin is generally accepted as a strong marker of the nutritional status. ${ }^{16}$ In some studies, low albumin has been associated with prolonged hospital stay, increased complications, and mortality. ${ }^{17-19}$ The disadvantage of albumin is that the protein has a relatively long half-life (18-20 days), and its change in concentration depends on the patient's body water balance. Therefore, the parameter is not considered to be sensitive enough to reliably diagnose malnutrition. ${ }^{20}$ Because the serum protein concentration can be maintained over a long period of reduced food intake or fasting at the expense of skeletal muscle mass, a reduction of muscle strength may occur even before changes in the plasma protein develop. ${ }^{21}$ Consequently, changes in body composition can occur before a shift of the serum protein concentration, which explains the low agreement between albumin levels and the data of the bioimpedance analysis in the present study.

Albumin levels should be used only for the verification of a suspected malnutrition or to estimate the extent of an existing malnutrition, carefully considering the halflife of the protein and the further diagnoses of the patient. Meanwhile, low albumin levels, regardless of the underlying cause, remain an independent prognostic factor for the overall survival of cancer patients. ${ }^{22}$ Because albumin has a short half-life of about 2 days, pre-albumin levels react quickly to changes of the food supply and are therefore suitable to reflect the nutritional status of a patient and to determine the success of a nutritional intervention. In case of insufficient food intake, the plasma concentration of pre-albumin decreases significantly after 3 days. ${ }^{23} \mathrm{On}$ the one hand, the synthesis rate of pre-albumin depends on the nutritional intake of protein: sufficient supply increases pre-albumin plasma levels by $1 \mathrm{mg}$ per day. ${ }^{24}$ On the other hand, the serum concentration of pre-albumin - an acute phase protein - is elevated in severely ill patients with high inflammatory parameters. ${ }^{25}$ In the present study, 7 patients were classified as malnourished with pre-albumin values $\leq$ $0.15 \mathrm{~g} / \mathrm{L}$. Pre-albumin and RBP have a very good agreement and identified the same 5 patients in the study as malnourished. Pre-albumin testing classified 2 additional patients as malnourished. Both methods are interchangeable in the diagnosis of malnutrition, so the determination of both parameters in the clinical setting is not reasonable and economic. If the results are interpreted with regard to kidney or liver disease or inflammation of the patient, then pre-albumin is a reliable marker to identify malnutrition. ${ }^{20}$

In the present study, BIA was used to determine the body composition of the patient. BIA is easy to use, noninvasive, inexpensive, and requires little patient cooperation, so this method is also suitable for geriatric or severely impaired patients. ${ }^{26}$ In the process of malnutrition, fat-free mass and fat mass degrade and a shift in the balance of the body compartments can be observed. ${ }^{27}$ The bioimpedance analysis is particularly suitable for serial measurements, so that weight loss or gain can be assigned to the different body compartments even though tumor mass or water retention masks the loss of body weight. Multifrequent BIA-measurements allow the determination of hydration and identify fluid imbalances. The amount of total body water is reflected by body cell mass, a high ECM:BCM index and low musclecell ratio represent edema or ascites. Furthermore, imbalances are also well reflected by the raw data (phase angle, reactance, resistance). With respect to these parameters, patients' water-balance can be interpreted.

Because the phase angle is also a good predictor of clinical outcome, ${ }^{28}$ we determined it to assess the nutritional status of the study patients, and we used age-, gender- and BMI-specific reference values from Bosy-Westphal and colleagues to evaluate the results. ${ }^{29}$

In the present study, 17 patients were classified as malnourished with a phase angle $\leq 5$ th percentile. The comparison of means was not significant and the analysis of agreement showed weak agreement for albumin, prealbumin and RBP and a low agreement for NRS-2002 and ECM:BCM. In patients with lung or colon cancer or $\mathrm{HIV}$, the phase angle has been described as a prognostic marker for mortality. ${ }^{30-32}$ It is hypothesized that the phase 
angle acts as a surrogate marker of catabolic processes and is therefore an independent prognostic marker of clinical course and mortality. ${ }^{32}$ Norman and colleagues showed that disease-associated weight loss is accompanied by loss of body cell mass and dysfunction of cell membrane integrity and is associated with a decreased number of intact cell membranes. ${ }^{28}$ In addition, the amount of fat-free mass has a prognostic significance, because it is associated with longer hospital stay, ${ }^{33}$ decreased immune function, and increased mortality. ${ }^{34}$

In healthy, normally hydrated persons, the amount of $\mathrm{BCM}$ is greater than the amount of ECM, so that the ratio ECM:BCM is $<1$. In individuals with disturbance of body water balance or in the catabolic state, this ratio shifts and reaches values $>1$. In the present study, the comparison of means showed that patients with an ECM:BCM ratio $>1$ had significantly lower pre-albumin, lower phase angle and a decreased cell content than patients with a normal ECM:BCM ratio. In the analysis of agreement only a weak agreement between ECM:BCM ratio and phase angle was observed. Since the statement of the ECM:BCM ratio on the nutritional status of a patient is limited due to body water balance disturbances, the interpretation of the ratio should be done in view of the overall condition of the patient. However, it should be considered that the reason for body water disturbances in severely malnourished patients is often the loss of serum protein, especially albumin.

Patients were included regardless of their primary diagnosis and tumor stage which might be a limitation of this study. On the other hand, our trial is the first that proved the comparability of different diagnostic tests assessing the nutritional status in the routine setting of a University hospital for Hematology and Oncology. Other trials have been

\section{References}

1. Sanchez-Lara K, Ugalde-Morales E, Motola-Kuba D, Green D. Gastrointestinal symptoms and weight loss in cancer patients receiving chemotherapy. Brit J Nutr. 2013;109:894-897.

2. Pirlich M, Schutz T, Norman K, et al. The German hospital malnutrition study. Clin Nutr. 2006;25:563-572.

3. Shaw C, Fleuret C, Pickard JM, Mohammed K, Black G, Wedlake L. Comparison of a novel, simple nutrition screening tool for adult oncology inpatients and the Malnutrition Screening Tool (MST) against the Patient-Generated Subjective Global Assessment (PG-SGA). Support Care Cancer. 2015;23:47-54.

4. Andreyev HJ, Norman AR, Oates J, Cunningham D. Why do patients with weight loss have a worse outcome when undergoing chemotherapy for gastrointestinal malignancies? Eur J Cancer. 1998;34:503-509.

5. Pirlich M, Schwenk A, Müller MJ, unter Mitarbeit von JOSSSV. DGEM-Leitlinie Enterale Ernährung: Ernährungsstatus. Aktuelle Ernährungsmedizin. 2003;28:10-25.

6. Elia M, Stratton RJ. An analytic appraisal of nutrition screening tools supported by original data with particular reference to age. Nutrition. 2012;28:477-494.

7. van Bokhorst-de van der Schueren MA, Guaitoli PR, Jansma EP, de Vet HC. Nutrition screening tools: does one size fit all? A systematic review of screening tools for the hospital setting. Clin Nutr. limited to patients with a particular entity, for example patients with lung cancer. ${ }^{35}$

\section{Conclusion}

We were not able to identify a single method that is reliable and applicable enough to be a reference tool in the diagnostic work-up for the identification of undernourished patients or those at risk of malnutrition. We therefore advise to implement one of the established screening questionnaires to detect patients with general nutritional problems in the clinical routine and to determine serum proteins with a short half-life (pre-albumin or RBP). Those methods for the identification of body composition (eg, BIA) are suitable for a more subtle diagnostic work-up, and these methods might be appropriate to monitor the success of a nutritional therapy, but not applicable in most facilities. The sole determination and interpretation of the $\mathrm{BMI}$ is not recommendable, because protein-energy-malnutrition could not be detected by this parameter. Eligible methods should be selected and implemented in respect of available resources. In undernourished patients nutritional intervention should be considered from the beginning as a part of the tumor treatment to maintain or to improve the nutritional status of patients who are unable to meet a sufficient caloric requirement.

\section{Acknowledgments}

BIA-unit and software was kindly provided by Fresenius Kabi, Bad Homburg; Germany. Author contributions: C Leithold, K Jordan, and $\mathrm{J}$ Rüssel were involved in the conception and design of the study; C Leithold, F Jahn, T Behlendorf, J Schaffrath, and C. Müller-Tidow were responsible for data collection and assembly. All authors reviewed and provided input on the outline and manuscript drafts, and provided final approval for manuscript submission.

2014;33:39-58.

8. Kondrup J, Allison SP, Elia M, Vellas B, Plauth M. ESPEN guidelines for nutrition screening 2002. Clin Nutr. 2003;22:415-421.

9. Biesalski HK, Bischoff SC, Puchstein C. Ernährungsmedizin: Nach dem Curriculum Ernährungsmedizin der Bundesärztekammer und der DGE. Thieme, Stuttgart; 2010.

10. Sun SS, Chumlea WC, Heymsfield SB, et al. Development of bioelectrical impedance analysis prediction equations for body composition with the use of a multicomponent model for use in epidemiologic surveys. Am J Clin Nutr. 2003;77:331-340.

11. Dallal GE, Wilkinson L. An analytic approximation to the distribution of lilliefors's test statistic for normality. the American statistician. 1986;40:294-296.

12. Sachs L. Statistische methoden: planung und auswertung 22. Springer; Berlin. 1990.

13. Grouven U, Bender R, Ziegler A, Lange S. [Comparing methods of measurement]. Dtsch Med Wochenschr 2007;132(suppl 1):e69-73.

14. Young VR, Marchini JS, Cortiella J. Assessment of protein nutritional status. J Nutr. 1990;120(suppl 11):1496-1502.

15. Shenkin A. Impact of disease on markers of macronutrient status. Proc Nutr Soc. 1997;56(1B):433-441.

16. Ryu SW, Kim IH. Comparison of different nutritional assessments in detecting malnutrition among gastric cancer patients. World J 
Gastroenterol. 2010;16:3310-3317.

17. Gibbs J, Cull W, Henderson W, Daley J, Hur K, Khuri SF. Preoperative serum albumin level as a predictor of operative mortality and morbidity: results from the National VA Surgical Risk Study. Arch Surg. 1999;134:36-42.

18. Delgado-Rodriguez M, Medina-Cuadros M, Gomez-Ortega A, et al Cholesterol and serum albumin levels as predictors of cross infection, death, and length of hospital stay. Arch Surg. 2002;137:805-812.

19. Lin MY, Liu WY, Tolan AM, Aboulian A, Petrie BA, Stabile BE. Preoperative serum albumin but not pre-albumin is an excellent predictor of postoperative complications and mortality in patients with gastrointestinal cancer. Am Surg. 2011;77:1286-1289.

20. Devoto G, Gallo F, Marchello C, et al. Pre-albumin serum concentrations as a useful tool in the assessment of malnutrition in hospitalized patients. Clin Chem. 2006;52:2281-2285

21. Russell DM, Leiter LA, Whitwell J, Marliss EB, Jeejeebhoy KN. Skeletal muscle function during hypocaloric diets and fasting: a comparison with standard nutritional assessment parameters. Am J Clin Nutr. 1983;37:133-138.

22. Evans WK, Nixon DW, Daly JM, et al. A randomized study of oral nutritional support versus ad lib nutritional intake during chemotherapy for advanced colorectal and non-small-cell lung cancer. J Clin Oncol. 1987;5:113-124.

23. Bernstein L, Pleban W. Pre-albumin in nutrition evaluation. Nutrition. 1996;12:255-259

24. Bernstein LH, Leukhardt-Fairfield CJ, Pleban W, Rudolph R. Usefulness of data on albumin and pre-albumin concentrations in determining effectiveness of nutritional support. Clin Chem. 1989;35:271-274.

25. Davis CJ, Sowa D, Keim KS, Kinnare K, Peterson S. The use of prealbumin and $\mathrm{C}$-reactive protein for monitoring nutrition support in adult patients receiving enteral nutrition in an urban medical center. JPEN J Parenter Enteral Nutr. 2012;36:197-204.

26. Kyle UG, Bosaeus I, De Lorenzo AD, et al. Bioelectrical impedance analysis-part II: utilization in clinical practice. Clin Nutr.
2004;23:1430-1453.

27. Barendregt K, Cox-Reijven PL, van den Hogen E, Beijer S, Geerlings P, Soeters PB. Case study of the clinical usefulness of bioelectrical impedance spectroscopy in evaluating nutritional status. J Hum Nutr Diet. 2002;15:189-192.

28. Norman K, Smoliner C, Kilbert A, Valentini L, Lochs H, Pirlich $\mathrm{M}$. Disease-related malnutrition but not underweight by BMI is reflected by disturbed electric tissue properties in the bioelectrical impedance vector analysis. Brit J Nutr. 2008;100:590-595.

29. Bosy-Westphal A, Danielzik S, Dorhofer RP, Later W, Wiese S, Muller MJ. Phase angle from bioelectrical impedance analysis: population reference values by age, sex, and body mass index. JPEN J Parenter Enteral Nutr. 2006;30:309-316.

30. Gupta D, Lammersfeld CA, Burrows JL, et al. Bioelectrical impedance phase angle in clinical practice: implications for prognosis in advanced colorectal cancer. Am J Clin Nutr. 2004;80:1634-1638.

31. Toso S, Piccoli A, Gusella M, et al. Altered tissue electric properties in lung cancer patients as detected by bioelectric impedance vector analysis. Nutrition. 2000;16:120-124.

32. Schwenk A, Beisenherz A, Romer K, Kremer G, Salzberger B, Elia M. Phase angle from bioelectrical impedance analysis remains an independent predictive marker in HIV-infected patients in the era of highly active antiretroviral treatment. Am J Clin Nutr. 2000;72:496-501.

33. Pichard C, Kyle UG, Morabia A, Perrier A, Vermeulen B, Unger P. Nutritional assessment: lean body mass depletion at hospital admis sion is associated with an increased length of stay. Am J Clin Nutr. 2004;79:613-618

34. Roubenoff R, Kehayias JJ. The meaning and measurement of lean body mass. Nutr Rev. 1991;49:163-175.

35. Li R, Wu J, Ma M, et al. Comparison of PG-SGA, SGA and bodycomposition measurement in detecting malnutrition among newly diagnosed lung cancer patients in stage IIIB/IV and benign conditions. Med Oncol. 2011;28:689-696. 